\title{
Book Review: Mason's World Encyclopedia of Livestock Breeds and Breeding
}

\author{
Francesco Vizzarri ${ }^{1}$ \\ ${ }^{1}$ Department of Agricultural, Environmental and Food Sciences, University of Molise, Campobasso, Italy \\ Correspondence: Francesco Vizzarri, Department of Agricultural, Environmental and Food Sciences, University \\ of Molise, Via De Sanctis, 86100 Campobasso, Italy. E-mail: francesco.vizzarri@unimol.it
}

Online Published: December 15, 2016

doi:10.5539/jas.v9n1p231 URL: http://dx.doi.org/10.5539/jas.v9n1p231

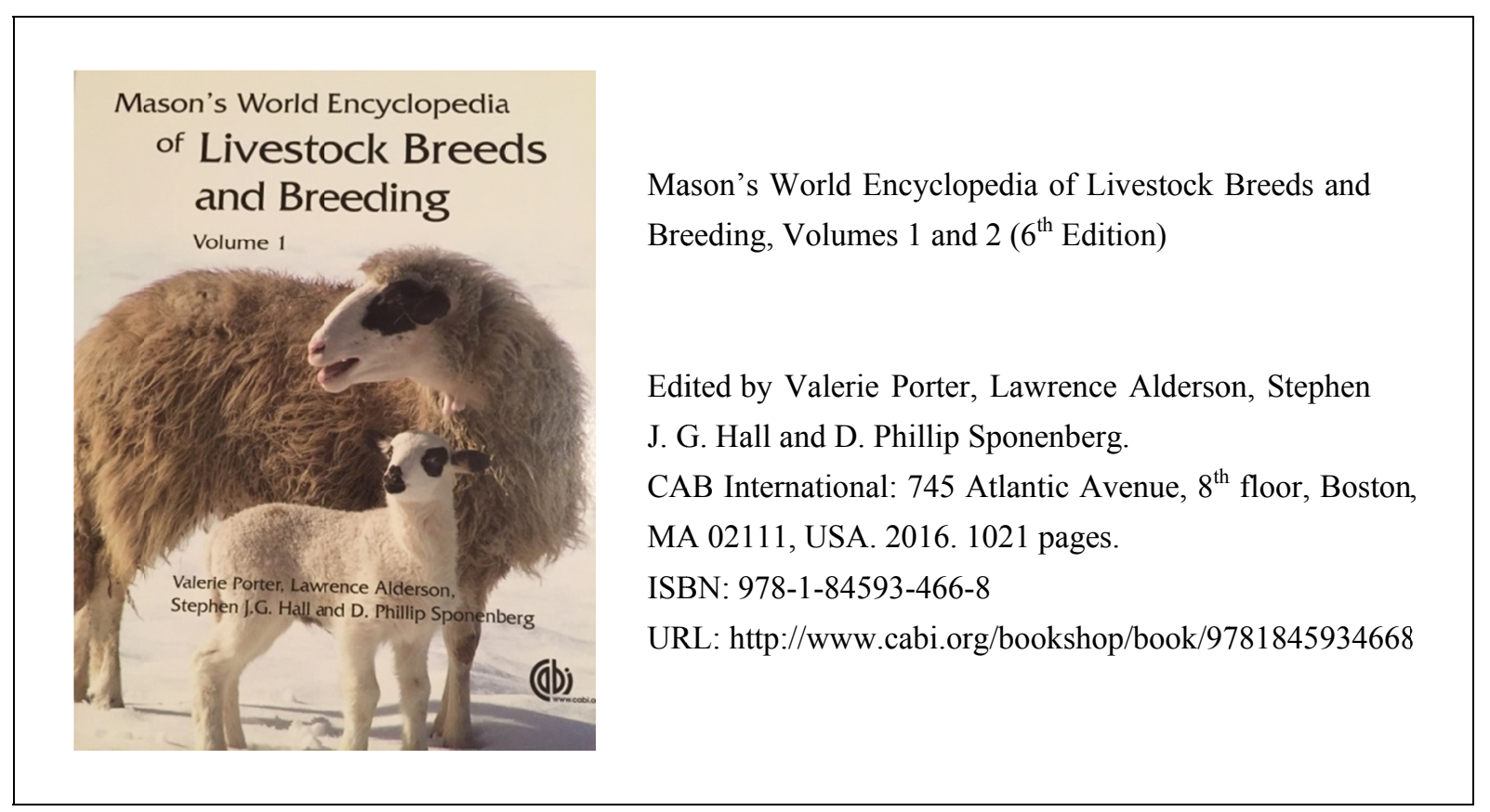

\section{Summary of Review and Endorsements}

Mason's World Encyclopedia of Livestock Breeds and Breeding represents a useful and suitable source of complete information on cattle, buffalo, horses, pigs, sheep, asses, goats, camelids and other livestock. These two volumes present a unique, comprehensive and fully cross-referenced guide to findings, evidences and reports on domestication (including wild ancestors and related species), potential domesticants, genetics and breeding, as well as cultural and social aspects of livestock farming, genetic conservation and the use of livestock for conservation grazing. Finally, in both volumes, all chapters end with a list of references and further reading. Written and edited by renowned livestock authorities, this livestock Encyclopedia will be an advantageous and helpful tool for scientists and researchers in writing papers, as well as for common reader who wants to learn knowledge and/or curiosities on this interesting topic.

\section{Body of the Volume 1 Review}

Both volumes (1 and 2) of the Mason's World Encyclopedia of Livestock Breeds and Breeding open with a chapter on breeding, genetics and conservation, in which Author presents interesting cross-link aspects between history and animal science. It is also reported a wide and exhaustive terminology section, useful for the reader to better understand the full encyclopedia. 
In the Asses chapter, recent data on global distribution and consistent are presented, and where possible it has added a historical context concerning the evolution of the breeds.

Chapter on Camelids opens with in a comprehensive manner description of the specie origin and taxonomy. A well-defined presentation of the domestication process, ties with the territory and different Camels and Lamoids breeds is explained.

The full-bodied chapter on Cattle begins with the display of recent data on global distribution and consistent. Wide, exhaustive and well-referenced considerations on origin of cattle, its domestication process and recent classification, inclusive of historical context, of breeds are provided.

In the chapter on Goat, emphasis was placed on the high adaptability of the species (defined as the "poor man's cow"). There is a wide-ranging description of coat, even in terms of fibre quality and different uses. An extensive description of wild breeds on global scale is offered; whereas a detailed description of the process of domestication introduces to all reared breeds for multiple farming systems.

Distribution and consistent, deep description of coat color, major uses, ancestral genetic lines and domestication process open the Horse chapter. After the classification of blood system (hot, cold and warm) and the breed groups, there is wide and comprehensive illustration of all reared breeds for multiple farming systems. Where possible it has added an historical context concerning the evolution of the breeds.

Pigs chapter is characterized by recent data on global distribution of species; it is given a wide presentation of different uses of pigs, with particular regards to meat production and different commercial cuts. Well-defined and synthetic notions on pig physiology and different colors of coats are reported. In addition there is an extensive description of wild species and an in-depth presentation of the domestication process that has led to the worldwide breeding of pig breeds, preceded by notions of pig genomic and classification of different breed groups.

\section{Body of the Volume 2 Review}

The Sheep chapter starts with a report of the genetic lines currently distributed in the world, all of them arising from one ancestral line (Ovis) of 3 milion years ago. The different domestication processes concerning ovis species are also defined and well described. In addition wide notions are provided about the physiology, conformation, multiple farming systems, as well as the description of all worldwide sheep breeds.

In the Water Buffalo chapter, Author comments the economic importance of this species, followed by a comprehensive description of the taxonomy to avoid any confusion. After clear concepts concerning the productivity of the species, all the breeds worldwide reared are presented. Where possible it has added an historical context concerning the evolution of the breeds.

In the Yak chapter, it is provided a complete explanation of the taxonomy, inclusive its worldwide distribution and consistent. Physiological notions are also delivered, in particular the extraordinary feature of environmental adaptation to extreme altitudes and temperatures of the yak. Subsequent to the domestication process description that has affected the yak, all breeds are presented.

In the last chapter of the second Encyclopedia volume, Author provides general knowledge (morphology, physiology, animal consistent and distribution, multiple farming systems) of other livestock species (wild and domestic) such as Elephants, Cervidae, Moschidae, Antelope, Buffalo and Bison, Musk Ox, Rabbits, Rodents, Cane rat and Guinea pig. 


\begin{abstract}
About the Book Authors
Volume 1

Breeding, Genetics and Conservation Chapter: Alderson Lawrence is an International Consultant on Animal Genetic Resources and Chairman of Countrywide Livestock Ltd., UK.

Asses, Camelids, Goats, Pigs Chapter: Porter Valerie is the Editor of Mason's World Dictionary of Livestock Breeds and author of various books on cows, chickens, pigs, goats, and sheep. She lives in Milland, West Sussex, in the United Kingdom.

Cattle Chapter: Hall Stephen works for Livestock Diversity Ltd and Stephen Hall is an Associate Lecturer in the College of Science at the Department of Biological Sciences, University of Lincoln, UK and Alderson Lawrence is an International Consultant on animal genetic resources and Chairman of Countrywide Livestock Ltd., UK.

Horses Chapter: Sponenberg Phillip is Professor of Pathology and Genetics at the Virginia-Maryland Regional College of Veterinary Medicine, Virginia Tech, Blacksburg. He works on rare breed conservation, largely through the American Livestock Breeds Conservancy.

Volume 2

Breeding, Genetics and Conservation and Sheep Chapter: Alderson Lawrence is an International Consultant on Animal Genetic Resources and Chairman of Countrywide Livestock Ltd., UK.
\end{abstract}

Water Buffalo, Yak and Other Livestock Chapter: Porter Valerie is the Editor of Mason's World Dictionary of Livestock Breeds and author of various books on cows, chickens, pigs, goats, and sheep. She lives in Milland, West Sussex, in the United Kingdom.

\title{
Copyrights
}

Copyright for this article is retained by the author(s), with first publication rights granted to the journal.

This is an open-access article distributed under the terms and conditions of the Creative Commons Attribution license (http://creativecommons.org/licenses/by/4.0/). 